\title{
A sociological exploration of the need for safe spaces for lesbian and gay students on a South African university campus
}

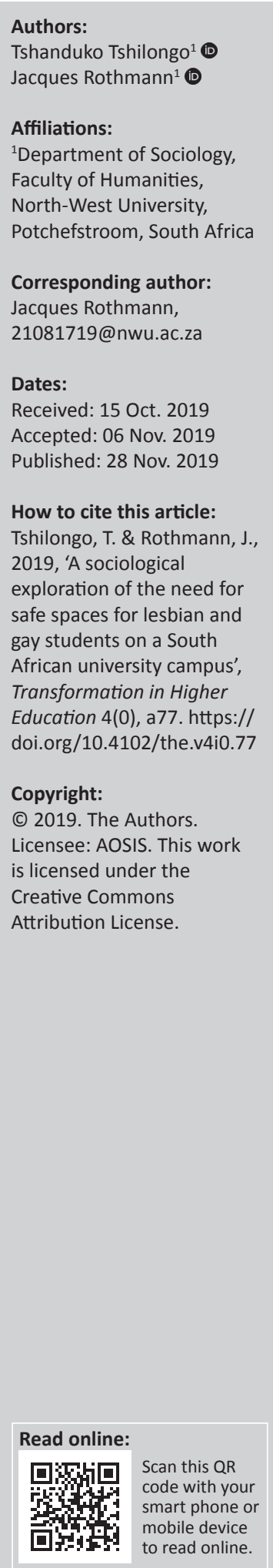

Background: The role of safe spaces on university campuses for gay and lesbian students remains a contested issue. This is attributed to the fact that the visibility of these students on university campuses presents a duality: On the one hand, the creation of such spaces provides a sense of communal belonging, safety and visibility for these students which could contribute to de-mystifying stereotypes. On the other hand, such increased visibility may further exacerbate a backlash to those who disclose their sexual identity, which manifests in verbal and/or physical homophobia.

Aim: The article reports on an explorative sociological study on the need for such safe spaces for lesbian and gay students on North-West University's Potchefstroom campus.

Setting: The focus of the research was to explore the need for safe spaces on the North-West University's Potchefstroom campus. The aim was to investigate the perceptions of selfidentified gay and lesbian students on the importance of providing such spaces.

Methods: A qualitative research design, informed by the meta-theoretical principles of social constructionism, interpretivism and queer theory, was applied. Probability and snowball sampling methods were used along with 20 semi-structured interviews with 10 self-identified gay and 10 self-identified lesbian students. Thematic analysis was used to code the data.

Results: Participants expressed dualistic narratives regarding their experiences on campus. Some indicated that they did not experience any discrimination whereas others recalled particular incidences of homophobia. These differences notwithstanding, participants provided particular definitions of such spaces, identified its preferred formations and reasons for being in favour of and against its implementation.

Conclusion: Findings suggest that the introduction of formal policies is essential in deciding on whether safe spaces are necessary and to inform the decisions of students require this to disclose their identities.

Keywords: gay and lesbian students; heteronormativity; homonormativity; homophobia; queer theory; safe spaces.

\section{Introduction}

In South Africa and other African countries, discrimination against gender and sexually diverse individuals has escalated from ideological condemnation of homosexuality to physical violence (Mendos 2019). Some individuals have been publicly humiliated, assaulted, raped, imprisoned or killed (Msibi 2009). The Equity Clause Sections 9(3) and 9(4) in the South African Constitution (RSA 1996) prohibit discrimination based on sexual orientation. With the introduction of democracy came the pledge that people who identify themselves as counter-heterosexual would benefit from the constitutional provisions, including the freedom of sexual affiliation, movement and access to information (De Palma \& Francis 2014). However, many South African institutions, including schools and universities, legitimise heteronormativity and cisgenderism (Brown \& De Wet 2018; Francis 2019; Richardson 2008). This inhibits attempts at emphasising the importance of transformative agendas that foreground the acknowledgement of protecting sexually diverse persons, alongside foci on the gender and racial identity of individuals - an argument to which Francis (2017a, 2017b) and Msibi (2013) attest.

Heterosexism may further fuel homophobia. This includes any form of behaviour (verbal and/ or physical) originating from prejudice, discrimination, stigmatisation or heterosexism expressed 
towards self-identified gender and sexually diverse persons or those who are presumed not to be heterosexual (Rothmann 2014). Studies undertaken on the experiences of sexual minority students in Canada (Grace 2015, 2017; Grace \& Benson 2000) and America (Chang 2005; Fox \& Ore 2010; Rankin 2006), among others, are well documented. There is evidence of a growing field of academic inquiry in South Africa on the theme. Foci in this regard centre mainly on the violence, prejudice and harassment faced by them in education contexts (Francis 2017a; Francis \& Msibi 2011; McArthur 2015; Richardson 2008; Sithole 2015); exclusion of gender and sexually diverse voices in university policies and curricula (Msibi 2015); negative perceptions about lesbian, gay and bisexual students (Arndt \& De Bruin 2006; Bhana 2014; Butler et al. 2003; De Wet, Rothmann \& Simmonds 2016; Rothmann \& Simmonds 2015); and the lived experiences of these students on campuses nationally (Hames 2007; Jagessar \& Msibi 2015; Lesch, Brits \& Naidoo 2017; Rothmann 2014; Tshilongo 2018). Only a few studies have explored the need for support at the institutional level of universities to develop policies and implement support services and safe space programmes for sexual minorities (Biaggio et al. 2003; Finkel et al. 2003; Neumann 2005) as a possible solution to address the issue of homophobia on university campuses.

The current article echoes the call for a localised focus on the experiences of and possibilities for gender and sexually diverse persons in education institutions in the global South (Graziano 2004; Nduna et al. 2017). The writers engage the findings from a 2017 explorative sociological study on the need for such safe spaces for lesbian and gay students on North-West University's (NWU) Potchefstroom campus. The reader is provided with an overview of relevant literature and theory, the research methodology and research findings, critical discussion and recommendations for future consideration. The specific research foci that inform the article's empirical discussion include the following themes: The positive features associated with safe spaces on the Potchefstroom campus of the NWU; the limitations associated with the implementation of such safe spaces; the possible forms safe spaces take; and the reasons in favour and/or against developing safe spaces on the said campus.

\section{Literature review and theoretical argument}

A safe space is a place where bigotry and discrimination against gender and sexually diverse individuals are not tolerated. These contexts provide places where supporting and understanding the challenges of sexual minorities are important in redressing campus contexts that leave lesbian and gay students fearing for their safety, keeping their identities undisclosed, experiencing harassment and feeling that their universities do not accommodate gender and sexual minorities (Beemyn \& Ranking 2016; Hind 2004; Poynter \& Tubbs 2008; Ratts et al. 2013). Locally, safe spaces manifest in varied forms: A person, a programme or a gay and lesbian student organisation. Some universities, abroad and in South Africa, have developed safe spaces and ally programmes to increase visible support for gender and sexually diverse students (Sanlo, Rankin \& Schoenberg 2002). University student organisations exist across the country and courses on gender and sexual diversity are taught. The main objectives of these spaces include improving the campus climate and environment for gender and sexually diverse students, increasing awareness of homophobia, encouraging conversations around gender and sexual diversity matters, and educating its members to challenge homophobia and heterosexism (Tshilongo 2018). Such spaces are designed to create alliances among those who defend the rights of the sexual minorities and to limit or challenge stereotypical views by a heterosexually dominant community (Fox 2007).

To implement and / or restructure university policies to redress homophobia, De Wet (2017:128), writing from a South African perspective, proposes a clear conceptualisation and implementation of courses focussing on '[H]uman rights literacies that would promote transformative action by lecturers, state and school/university officials, teachers ... [and] students' to include mastering particular skills and using specific language to encourage people to engage critically in debates on gender and sexual diversity and equality (Kumashiro 2002; Msibi 2015). Restructuring may also require the redevelopment of the curriculum (across faculties, from undergraduate to postgraduate levels), student amenities, and faculty and staff training (Francis 2013, 2017b; Rothmann 2014). For the redevelopment of the curriculum, Rothmann and Simmonds (2015) suggest courses that address issues on sexuality (either as stand-alone courses or content incorporated into modules of mainstream programmes and curricula). Classes could incorporate discussions on the contributions of gay and lesbian politicians and activists, thereby addressing the superiority and inferiority binary. Selfidentified gay and lesbian lecturers may facilitate a more positive atmosphere in the classroom based on their first-hand account and provide a more balanced and detailed view of the experiences of gender and sexually diverse persons (Rothmann 2014). How the university culture, climate and curriculum restrict and create barriers for students should be recognised (Jagessar \& Msibi 2015).

Fox (2007) critiques safe spaces for creating an exclusionary and segregated community for sexual minority students, which may lead to a 'freezing of difference' (Fox \& Ore 2010:634). Francis (2017b:100) and Robinson and Ferfolja (2001:124) argue in favour of creating a more intersectional space as individuals' sexuality is always intertwined with the 'whole subject'. Francis's (2017b:100) study on the lived experiences of sexual minority youth provides an example: '[T] he youth described their life worlds as the sum of many parts, which included but was not limited to their sexual orientation'. The discourse on safe spaces fails to justify this intersectionality; it relies on a binary logic that emphasises the eradication of homophobia/heterosexism. Fox (2007) avers that this inhibits the establishment of a reciprocally beneficial relationship between the homosexual students and the 
broader campus community. It is essential to study the experiences of gay and lesbian students as distinct and not as homogeneous (Judge 2017), and also to implore a critical investigation of how identities and experiences result along intersectional lines of ethnic, racial and gender identities in different South African institutions (Bhana 2012; Francis 2017b; Msibi 2013, 2015; Oswin 2007), regardless of the constitution. Rothmann (2018) and Van den Berg (2016) do, however, contend that such 'strategic essentialism' (see the work of Spivak 1987) does not necessarily solely homogenise the experiences of gay and lesbian students in a communal setting. By 'temporarily assimilating' into a supposed homogeneous setting, agentic students identify 'their shared experiences [with other students], yet diverse inter-subjective life-worlds' (Rothmann 2018:6). An intersection and discursive relationship between agency and structure thus arises.

Such agency notwithstanding, safe spaces may still encourage the enactment of the performed rituals that retain heterosexuality as a norm, necessitating sexual minorities in academic settings to assimilate into a heteronormative culture (Fox 2007; Milani \& Wolff 2015). Msibi (2013) encourages a critical view when using queer theory in studying African and South African contexts based, in part, on its Western origin. This notwithstanding, a queer theoretical view aids the researcher in analysing the implications of the creation of normative identity categories (e.g. heterosexuality and homosexuality) (Msibi 2013; Warner 1991). In keeping with the focus of the article, it is of particular interest to focus on the use of queer theory to scrutinise the interplay of heteronormativity with homonormativity, which may 'naturalise, normalise and legitimise some expressions of same-sex desire, at the expense of others' (Milani \& Wolff 2015:167) through the creation of safe spaces.

This study foregrounds how safe spaces contribute to and/or challenge heteronormativity and homonormativity by decentring solely Western analyses 'to get beyond the mere derision of the purported importation of a Western-style queerness' (Oswin 2007:658).

\section{Research methods}

The research topic applied social constructionism as an ontological approach and the epistemological approach of interpretivism - both associated with the central theoretical argument's queer theoretical focus (Bryman 2016). These approaches postulate that the nature of our social (and sexual) realities are constantly constructed and reconstructed through interaction (Creswell \& Creswell 2018). A qualitative research design provided an in-depth explanation of the gay and lesbian participants' subjective views on the need for safe spaces on the university campus. The objective of qualitative research centres on the accumulation of in-depth descriptions and the emphasis on the researcher's ability to understand, explain and explore phenomena (Creswell \& Creswell 2018).

The participants included 10 self-identified gay and 10 selfidentified lesbian students registered as undergraduate or postgraduate students of the NWU's Potchefstroom campus. Their average age was 22 years and they were all South African. The participants comprised eight white participants, nine who identified as black and three who self-identified as of coloured per racial category. Their faculties entailed engineering, law, arts, natural sciences, economic and management sciences, educational sciences and health sciences. They were identified through non-probability sampling methods of purposive and snowball sampling. Purposive sampling was performed on the basis that the participants had relevant and the best possible knowledge and expertise regarding the topic under investigation. This sampling method focussed on identifying participants who may form part of a minority 'hidden' group (Rumens 2011) owing to the sensitivity of the topic (O'Leary 2014). For the purpose of the study, some members of a student organisation on the campus consented to participate in the study. The participants were then requested to distribute the call to other self-identified gay and lesbian persons who might find the study of interest to participate in. After a detailed explanation of the background and the purpose of the study, participants were provided with an informed consent statement to sign. Through in-depth interviews, data were obtained by conversing according to an interview schedule that comprised three subsections: The biographical and academic background of gay and lesbian students and opinion-related questions (based on themes from the literature). With regard to interviews, confidentiality was ensured by having participants choose their own pseudonym at the start of the interview. In this study, most participants chose their own pseudonyms (cf. Ackerly \& True 2010). This notwithstanding, in some cases, participants allowed the researcher to provide them with pseudonyms.

This article foregrounds the following thematic subsections of the interview schedule: defining safe spaces, the forms safe spaces could take, arguments in favour of safe spaces and challenges associated with the implementation of safe spaces on the said campus. Interviews were conducted to explore the lived experiences of the participants. Each participant was informed that the duration of the interview would range from 1 to $3 \mathrm{~h}$ at a location of their choice. Most students preferred a more private space (e.g. the researcher's office and some students preferred the campus cafeteria). In this study, the participants were encouraged to relate their personal narratives in their own words (cf. Babbie \& Mouton 2001:289). None of the participants opted to leave during the interview. The interview narratives were transcribed and analysed through thematic analysis. Open and selective coding was used to code both existing themes and new themes from the data, comprising defining safe spaces, their forms, the arguments in their favour and their potential limitations. For the purpose of this study, the researcher adopted Braun and Clarkes' (2006) model of thematic analysis. The procedure included examining the interviews conducted with gay and lesbian students in order to uncover the recurring patterns of meaning, themes and ideas used to describe and understand homosexuality in a university context. Furthermore, specific codes were 
identified in order to highlight potential themes and patterns that emerged from the data. These themes are engaged in the subsections to follow.

Ethical principles were adhered to per the approved ethical clearance by the University's Faculty of Arts Ethics Committee, including voluntary participation, no physical or emotional harm to the participants and the protection of the participants' identity, that is, the protection of lesbian and gay students' identity in interviews (cf. Bryman 2016). Information on the protection of the participants' interests and their well-being formed part of the Informed Consent Statement. Confidentiality and privacy were included. Confidentiality, as noted above, was ensured by most participants choosing their own pseudonyms. Participants were not compelled to comment on issues they considered personal (Wilson \& MacLean 2011).

\section{Findings and discussion}

This is a quote from Batso (a lesbian participant) on the position of gay and lesbian students on the Potchefstroom campus:

'I have not heard of anyone in the university who has reported a crime against discrimination because of their sexuality, this may mean that because students are not aware of the policies or laws concerning sexual orientation, they find it hard to go and report the incident because they also do not know what to expect when they report the incident.' (Batso, lesbian, Arts)

This introduces and underscores the discussion on the dualistic experiences of gay and lesbian students, as it centralises the absence yet presence of discrimination on the campus. To link this thought to the need for safe spaces, this subsection focusses on a critical engagement with the research findings, and it relates to the definitions of such spaces by the participants, a delineation of the varied forms safe spaces could take and the reasons in favour of and against its implementation.

\section{Definitions of a safe space}

Safe spaces were mostly described as a physical place, denoting buildings (Thinus and Brenda, a gay and a lesbian student, respectively) or offices and people, where 'protection from harm' is important; where participants feel 'comfortable' with themselves, with an appreciation of difference and the context is 'free from homophobia' (Larry, a gay student). These descriptions substantiate Hind's (2004) definition of a safe space as one that manifests as a room, a person or a programme where discrimination against sexual minorities is not tolerated and where people can be themselves (cf. Plummer 2015). Some participants described a safe space as an environment or climate where marginalised people meet and discuss their issues on discrimination and where victimisation, hate speech and harassments are not tolerated (cf. Evans 2002).

\section{Forms of safe spaces}

The participants cited different examples of the forms of safe spaces:

\section{The University campus as a safe space or zone}

Seven participants argued that the campus environment displays the potential to empower students in learning, progressing and networking with friends in support of sexual minorities. This echoes Ghaziani's (2015) argument on how society may contribute to the inclusion and protection of homosexual individuals in South Africa and abroad (cf. Reddy 2010). A gay participant in Munyuki and Vincent's (2017:19) study among gay, lesbian and bisexual residency students on a largely residential South African campus noted that a positive experience of one's campus may allow 'you to establish your own values, it allows you to know yourself because it allows you to experience life'. Evans (2000) agrees that learning is enhanced when students feel validated and experience positive interactions with peers and the faculty, in and outside the classroom. Seven of the 20 participants noted that the university campus may be regarded as a safe space for gay and lesbian students, attributed from the findings of a university campus as a safe space if ally programmes that promote inclusivity of gay and lesbian students exist. Participants also indicated that people must be educated and sensitised about diversity and support for gay and lesbian students (cf. De Wet 2017; Grace 2006, 2015); this recalls De Wet et al. (2016), Kumashiro (2002) and Msibi's (2015) call for education of 'others' (through overt support and affirmation) and education about 'others' (knowledge to heterosexually identified students and staff about homosexuality). According to Boostrom (1998), such programmes may contribute to improved academic performance. The education and sensitisation about gay and lesbian students' issues may result in the development of inclusive policies and 'nurturing practices'. Increased sensitisation and consciousness among students and staff about issues related to homosexuality may encourage the management of education institutions to amend their policies to protect homosexual students against discrimination (De Wet 2017; Macgillivray 2004). These initiatives may furthermore encourage university staff members and students, their families and friends to participate in training sessions to become so-called 'safe spaces' and/or 'allies' for potential victims (Evans 2000, 2002).

It was also of interest that, irrespective of their self-identified racial category, some participants argued that they were openly gay and lesbian on and off campus. This was attributed to, among others, the openmindedness of their families on a structural level and on an individual level, their own personalities, self-confidence and self-acceptance, which recalls the reference of Cass (1979) to 'identity synthesis' as an example of experiencing identity pride. Examples of this include Tshiamo, a self-identified coloured gay student, who argues that:

'[I]t is important to display characteristics associated with gay identity because it often works to your advantage, when I display characteristics associated with my identity I am saying that I am comfortable with who and what I am, unlike those who do not display it, because they are afraid of adversity. For example, I believe myself to have a feminine speaking tone and I am okay and comfortable ${ }^{1}$ with it.' (Tshiamo, gay, Arts)

1.Emphasis added. 
Bob, a self-identified white gay Faculty of Arts student, embraced particular stereotypes associated with his sexual orientation; he argues that 'I have always seen myself as flamboyant and I think that's what characterises my gay identity. I think the gay identity is oftentimes associated with flamboyance and outspokenness'. Three self-identified lesbian students, Ellen, Sally and Zack, irrespective of their race, also indicated that their sexuality is not only characterised by their attraction to other women but also manifests in their physical appearance and the activities they like to openly engage in. They felt free and liberated to express their sexuality and were therefore afforded an opportunity to make choices on how they live their personal lives, denoting an acceptance of their supposed 'otherness' rather than its subordination (Plummer 2015).

\section{One-to-one consultations}

It should be acknowledged that one-to-one consultations with lecturers, psychiatrists, psychologists and social workers (Evans 2000; Nel, Rich \& Joubert 2007) may contribute to support for gay and lesbian students. Eight participants thought that one-to-one consultations might be safe spaces, an evident belief supported by Evans (2002), Grace (2006) and Harper et al. (2007). These students noted that this requires that psychologists, psychiatrists and other mental health professionals based on the university campuses must understand the individual experiences of gay and lesbian students as well as the structural constraints presented by the campus culture (e.g. potential homophobia) (Francis 2017a; Jagessar \& Msibi 2015). Six participants commented on the importance of one-to-one consultation for students' health. Zintle, a lesbian law student, noted how this could contribute to reducing depression levels and, as Precious, a lesbian arts student argued, less inclination to suicidal tendencies on the part of the students. Such support, according to these students, could redress the exacerbation of increased levels of internalised homophobia and marginalisation (Evans 2002; Harper et al. 2007). Zintle stated the following in this regard:

'[S]ome people have difficulty loving and accepting who they are; they are often depressed and counselling can help them explore barriers to self-esteem and teach them ways in which they can make their happiness a priority.' (Zintle, lesbian, Law)

Thus, support from these professionals may contribute to students' higher levels of self-esteem and confidence (Grace 2006).

\section{The classroom as a form of safe space}

Eleven participants cited the significance of their classrooms as safe spaces; some noted that this context may become a safe space if lecturers and fellow students discourage the use of discriminative language during lectures, which might result in sexually diverse individuals feeling less judged by others (Francis 2019; Grace 2006; Kumashiro 2002; Msibi 2015). Three participants (Alan, Mario \& Lungile) noted that a classroom as a safe space may be created through educating other students about the history, lives and the experiences of gay and lesbian people (Richardson 2008). According to
Kumashiro (2002), this is referred to as 'education about the others', and 'calls educators to bring visibility to ignored issues' (Msibi 2015). Brown (2018:17) reaffirms this point by foregrounding the importance of providing a more 'sophisticated understanding of the diverse identities that are converging within these spaces in order to create a safe and inclusive learning environment for all'. According to Ellen, a lesbian student in the Faculty of Education, an inclusive classroom is characterised by the acceptance of gay and lesbian students by including them in class discussions where they will not feel segregated. In doing so, these students may also feel free to express their views and ideas without any feeling of being judged. This acceptance may have positive impacts on students' academic performance and they may feel free to contribute during class discussions and group assignments, supporting Francis' (2013) use of Forum Theatre to expose students to creative and constructive methods of teaching and learning in a South African school (and university) setting. He argues that, notwithstanding some limitations of the approach, students could enact their agency to critically reflect on the principles associated with heteronormativity (Francis 2013; Msibi 2015; Rothmann \& Simmonds 2015). This underscores Kumashiro's (2002) and Msibi's (2013) arguments that the non- or underrepresentation of sexual minorities in higher education curricula stifles attempts to critique and transform heteronormative pedagogies.

The topicality and importance of implementing such course content at the university level currently intersect with the varied reactions to proposed changes in primary and secondary schools' gender and sexuality education curriculum. $^{2}$ The proposed changes envisage foci on an introduction of learners to the male and female genitalia (Grade 4); the 'normality' of masturbation (Grade 7); and identifying different forms of sexual orientation (Grade 8), among others (Nel \& Slatter 2019:1). Those against the envisaged changes, including representatives of the Christian pressure group, Freedom of Religion South Africa (FOR SA), have indicated their disapproval of how the curriculum 'normalises'3 homosexuality and uses particular persons, including HIV-treatment activist Zackie Achmat, athlete Caster Semenya and former Constitutional Court judge Edwin Cameron, as role models and heroes. They consider it problematic as some of these persons are HIV-positive and some identify as 'LGBT'. ${ }^{4}$

Nel and Slatter (2019) note that Chris Klopper, President of the South African Education Union, described the potential changes as 'grossly insensitive ${ }^{5}$ and encouraged 'boycotting' these views notwithstanding, proponents of the changes

2.The Rapport newspaper reported on the leak of proposed curriculum content on gender and sexual diversity in South African schools. Further meetings between the South African Education Union and the South African Department of Education are scheduled for late November 2019 to further engage these changes and their implications (Nel \& Slatter 2019).

3.Translated from Afrikaans: 'normalisering'.

4.Abbreviation used in the newspaper article.

5.Translated from Afrikaans: 'grof onsensitief'. 
applaud the curriculum's emphasis on 'permission, boundaries and respect ${ }^{\prime 6}$ which are in keeping with the constitution (Nel \& Slatter 2019:1). The Department of Basic Education (2019) critiqued what they considered to be ' $[F]$ alse reporting by some media organisations and fake news' that led to the 'unnecessary confusion and anxiety among parents in particular' and encouraged parents and the general public to provide inputs and raise concerns on the matter directly to them (Etheridge 2019). ${ }^{7}$ Irrespective of the views on the matter, such reactions, particularly as it relates to sexual orientation for the purpose of the article, leave us pondering the importance and implications of the decision to include gender and sexuality course content in university curricula, and its role in critiquing cisgender approaches to the topic. It is worth quoting Francis (2019) in this regard. He notes that social scientists should engage debates:

[A]bout the social significance of compulsory heterosexuality in South African education and argue for the need for engagement with gender and sexuality diversity not as competing with heterosexuality but in ways that suggest that compulsory heterosexuality has inevitable costs for all $^{8}$ learners (Francis 2019:785)

\section{Openly gay/lesbian lecturer}

Participants noted the desirability of having an openly gay/ lesbian lecturer, attributing their reasons to the role that these lecturers play in inspiring students and their positive influence through autobiographical 'life narratives', as favoured by, among others, Grace (2006). This echoes the work of Griffin et al. (2007), Petrovic and Rosiek (2003) and Rothmann $(2016,2017)$ who assert that lecturers could use autobiographies in class as spaces for disclosing issues that have been historically ignored or denied by providing a 'more nuanced, balanced and thick descriptive account of the experiences of sexual minorities' (Rothmann \& Simmonds 2015:8). However, participants commented on how the disclosure of their lecturer's sexual orientation in an education context may harbour potential threats, such as anxiety over potential institutional homophobia, stigmatisation, fear of exclusion and verbal and physical threats (Rothmann 2016, 2017; Warren 2008). Sally, a lesbian student, commented on how heteronormativity inhibited the efforts on the part of her openly gay lecturer to provide help to gay and lesbian students. She continued:

$[O] f t e n$ as a lesbian person I may not want to communicate my problems and experiences with, for example, straight people, but may find it constructive speaking to a lesbian or gay lecturer.

And the lecturer you thought might be of help and a role model 6.Translated from Afrikaans: 'toestemming, grense en respek' (Nel \& Slatter 2019:1).

7.The Department of Basic Education (2019) published the full lesson plans for its Comprehensive Sexuality Education (CSE) curriculum on its official website in November 2019. References to sexual orientation on primary school level included quotes of the Bill of Rights as part of the Grade 5 and 6 Learner Guides, whereas Grade 7 learners are introduced to short definitions for sex, gender and sexual orientation. High school foci include definitions and short discussions of concepts including 'gay', 'homosexual' and 'sexual orientation' and activities on sexua including 'gay', homosexual and 'sexual orientation' and activities on sexual violence directed toward 'innocent people' (e.g. 'gay women') in the Grade Learner Guide. There is a differentiation between the different sexual and gende The references to Zackie Achmat, Caster Semenya and Edwin Cameron appear in the Grade 11 Learner Guide (Department of Basic Education 2019)

8.Emphasis added. is unavailable to talk to students; it's as if their environment restricts them from discussing issues related to their sexual orientation (as) ... it might destroy their image ... (or) jeopardise their career. (Sally, lesbian, Engineering)

\section{Student organisations}

Risks and fears faced by gay and lesbian students may be curtailed by specific organisations or programmes that decrease the rates of harassment and violence to create a university context, which is relatively safer and supportive where such students may reach their full potential (Consortium of Higher Education LGBT Resource Professionals 2016). Those participants who viewed affiliation with a communal student organisation group as important, echoed the precepts underlined by theorists and social scientists whose work echoes the principles of queer liberationists (Eide 2010), who are argued to be dedicated to 'improving' (Jagose 1996:30) situations for homosexuals. Therefore, having a visible community and participating in such groups emphasise an organised assertion 'against heteronormative ideologies' (Seidman 2003:65) and sexual, gender and social inequalities resulting from these ideologies. Twelve participants regarded it as necessary to have such designated venues that are mainly for gay and lesbian students on campus. They indicated that such a venue may create a platform where gay and lesbian people can be visible, recognised and given the attention they need in safety, and policies against discrimination that are specific and reflective of their lived experiences. Two students noted that gay and lesbian students (and their organisations or movements) require and deserve equal privileges as other societies on campus. Tshiamo, a gay student, commented that:

'[J] ust like other societies that have their venues where they discuss issues concerning themselves, gay and lesbian students have to be awarded similar venues which may also help in empowering other gay and lesbian people.' (Tshiamo, gay, Arts)

Six gay and nine lesbian participants commented on the importance of having lesbian and gay student organisations to support and potentially persuade campus management to restructure and enact policies advocating the rights of gay and lesbian students to encourage constructive change (cf. De Wet 2017); also that university management should collaborate with a gay and lesbian student organisation to know how students experience the campus climate and the steps that must be taken to address the needs, challenges and contributions of gay and lesbian students (cf. Rothmann \& Simmonds 2015). Conversely, some noted a more negative view of communal safer spaces. Five participants noted that being part of a visible group is not necessarily significant. Participants referenced this insignificance to these groups being the 'culprits' or 'cause' for segregation and exacerbation of homophobia, as attested by Fox (2007). One participant noted that these groups, with some of their principles and ideologies, unconsciously uphold heteronormative precepts through their need for equality with heterosexual people, thus upholding the notions of assimilation which makes a case that gay and lesbian students deserve equal rights and 
acknowledgement (Milani \& Wolff 2015; Robson 2002). Adopting a post-structuralist stance, proponents of queer theory critique this thought, referring to the fact that sexual minorities should not merely be assimilated into an uncritical acceptance of heteronormative principles and ideologies (Epprecht 2010).

\section{Arguments in favour of creating safe spaces on the Potchefstroom campus}

\section{Defending the rights of gay and lesbian students and identifying and restructuring policies}

All participants reported that they were unaware of the policies protecting gay and lesbian rights on campus as postulated in similar studies by Biaggio et al. (2003) and Grace (2015). The NWU's Human Rights Policy (2016) and Diversity Statement (2006) are worth considering in this regard. The former was approved by the NWU Council in 2006 and reviewed and amended in 2012 (with only editorial changes), 2016 and is up for review in 2019. Guided by the democratic values of the constitution, that is, 'human dignity, equality and freedom', as part of its main objectives, the policy seeks to:

(1) $[P]$ romote a culture of human rights, and the observance, respect and protection thereof; [and] (2) develop an awareness of human rights among the university community and its external environment. (NWU 2016:1)

Although it is encouraging that this document foregrounds the importance of human rights, it is worth noting that observing the rights of persons based on their sexual identity is not mentioned explicitly in the policy. Considering, however, the overt emphasis on disability, gender and race: 'The members of the North-West University Human Rights Committee will be representative of the university community and will be sensitive to race, gender and disability' (NWU 2016:2). The NWU Diversity Statement, informed by the vision contained in the Education White Paper 3 (Department of Education 1997), echoes these sentiments as it seeks to:

- promote equity of access and fair chances of success to all - irrespective of race, colour, gender, creed, age or class seeking to realise their potential through higher education;

- support a democratic ethos and a culture of human rights by educational programmes and practices conducive to critical discourse and creative thinking, cultural tolerance and a common commitment to a humane, non-racist and non-sexist social order (NWU 2006:2). ${ }^{9}$

In the absence of an unequivocal reference to sexual orientation in both of the above, we encourage management, as do the participants of the study, to restructure these policies and statements to include sexual orientation alongside references to gender and race, evident in arguments in the work of Donaldson (2015) and Munyuki and Vincent (2017) on similar debates. This may, according to the participants of the study, benefit those gay and lesbian 9.Emphasis added. students who are struggling with their sexual identity and those who wish to defend themselves against homophobia. Although some felt unthreatened on campus, they believed it was important to have policies that attended to and 'dealt' with the needs of gay and lesbian students and staff, as these policies create a platform for other students to come out of the closet (cf. Consortium of Higher Education LGBT Resource Professionals 2016). Note that the various participants underlined the importance and the positive nature of formal policies that protect the rights of gay and lesbian students. Mario, a gay natural sciences student, noted that the reason why some students decide to remain in the closet is 'because they are not aware of the policies' that protect them, an argument to which Barrett et al. (2007) attest. The student further argues: '[I]f the university says that it embraces diversity it (must) make sure that those diverse groups complete their education free from violence or discrimination of any kind' (Mario, gay, Natural Sciences).

This may suggest that, without necessary policies, students are likely to feel unprotected against hate crimes or discrimination. It may further prevent them from reporting incidences of these crimes. It also became apparent that students considered the restructuring of policies to be inclusive of homosexual rights (particularly for those who have not disclosed their sexual orientation), as noted by Fox (2007), particularly in deciding about disclosing their identities. The construction of these spaces or policies potentially contributes to the affirmation of their identities and also challenges the system of 'compulsory heterosexuality' (Rich 2003). Likewise, Ratts et al. (2013) argue that the influence, which may arise from these spaces, may be used to benefit gay and lesbian students to positively improve the campus climate and regulate the university's policies and their execution. Some participants highlighted the importance of an organised and visible group on campus, 'especially if the group is a revolutionary movement to restructure or change policies to be inclusive' and 'there is a group ... willing to voice out ... and support you ... [in] coming out of the closet' (cf. Plummer 2015; Reddy 2010). This recalls Corrigan and Matthews's (2003) belief that it would benefit homosexual communities to be more visible to further their shared political and socio-economic needs.

Sensitisation: Another theme centred on how safe spaces provide students and staff, irrespective of their sexual orientation, with education and understanding of sexuality (cf. Francis 2017; Kumashiro 2002; Msibi 2015; Payne \& Smith 2011). Eleven students noted that safe spaces provide a platform for sensitisation, which might bring about an eradication of misconceptions and stereotypes of gay and lesbian students and may thus contribute to making the campus a 'safer' (Fox \& Ore 2010) and more inclusive space (Macgillivray 2004) to eradicate homophobic bullying (Birkett, Koenig \& Espelage 2009). One lesbian student argued that, through surveys or testimonials (Macgillivray 2004) monitoring students' experiences on campus, campus management may be encouraged to restructure policies to protect sexual minorities against discrimination. 


\section{Safe social networking and support}

One of the key themes that emerged on the potential positive features of safe spaces came from the six participants who commented on the importance of safe spaces in creating a positive platform for gay and lesbian students, a thought commented on by Alvarez and Schneider (2008) and Evans (2002). Batso, Brenda, Dee, Santo, Thinus and Tshiamo regarded safe spaces as safe social networking and 'fun' places as the university climate may often not be favourable; a safe space therefore becomes a 'safe haven' and a comfortable context where they could securely express themselves. This is supported by Hind (2004). Participants cited the importance of having gay and lesbian friends for social support. While some singled out gay and lesbian friends as the most likely support, they noted that potential sources for social resilience may come from different people or allies (Biegel 2010; Francis 2017; Rothmann 2014), including heterosexual friends and lecturers.

Bringing people together, according to Fetner and Elafros (2015:574), is one aim of safe spaces, substantiated in the narratives of the participants. According to Plummer (2015), such spaces tend to question the existing orders by mobilising resources (also mentioned by one student), setting up new practices (such as annual surveys), tactics and strategies through activist performance (policies, according to findings from participants) to diffuse into varied cultures and potentially challenge and change the social order. Aligned with Plummer's argument, Van den Berg (2016) asserts that it is a queer thinker's task to interrogate existing unjust principles that uphold disciplinary structures of conformity and visions of heterosexuality, which intimidate and constrain people's identities and life choices. Kumashiro's (2002) 'anti-oppressive education' paradigm is also evident as he too advocates providing a context where one could critically educate and sensitise individuals about the heteronormative 'othering' of sexual minorities (cf. Francis 2017b; Msibi 2015).

Regardless of these efforts, it would be remiss if a focus is not placed on the potential implications of creating and/or providing safe spaces on this campus.

\section{Challenges associated with the provision of safe spaces on the Potchefstroom Campus}

Regardless of the discussion on the importance of acknowledging sexual diversity and plurality along intersectional lines, one of the key themes raised by the participants was that safe spaces contribute to the creation of exclusive and marginalised communities (cf. Fox \& Ore 2010). Some noted that the influence of safe spaces may prevent members from concealing their identities if they so wish and how, through designated venues and organisations, these spaces tend to be segregated from the larger campus community (Robinson 2012) to provide only sexual minority students with, what WalshHaines (2012:15) refers to as, their 'place at the table'. With sexual minorities being oppressed through exclusion, these very spaces tend to engage in the practice of reverse discourse only changing the direction of power and not the foundational ideologies on which this discourse relies (cf. Foucault 1980). This results in embracing an originally oppressive discourse in a larger societal space (cf. Milani \& Wolff 2015); stereotypes, values and homogenised views of what it means to be gay or lesbian are not challenged or inhibited, but are rather intensified (Fox \& Ore 2010); and therefore result in the reinforcement of homonormativity. As noted by Alan, a gay Arts student, these safe spaces resemble 'stereotypically gay' organisations. One can engage the preceding reference to provide gay and lesbian students with 'similar venues. ${ }^{10}$ to 'discuss issues concerning themselves'.

Although one cannot generalise this quote, it is evidently informed by principles associated with homonormativity that do not contest the dominant heteronormative assumptions and institutions, but argue in favour of being assimilated into an existing heterosexual context, thus retaining heterosexuality as a normative ideal (Brown 2018; Butler et al. 2003; Jagessar \& Msibi 2015; Mwaba 2009) while potentially reinforcing a demobilised gay and lesbian constituency and a privatised gay culture (Rothmann 2017). This may result in, as evident in Jagessar and Msibi's (2015) research on the experiences of sexual minority students of the University of KwaZulu-Natal, gay and lesbian students internalising, normalising and even trivialising overt and covert heteronormative or homophobic treatment from others, as it is seemingly 'not all that bad' (Jagessar \& Msibi 2015:71), thus unwittingly providing 'organised consent' (Atkinson \& DePalma 2009) to the centrality of heterosexuality as opposed to homosexuality. This echoes the contributions of Lesch et al. (2017) on the experiences of same-sex student couples at the Stellenbosch University. Their findings reaffirmed the centrality of heterosexual hegemony; irrespective of efforts on behalf of the university's management to create a more 'inclusive' campus culture, lesbian students continued navigating between visibility and invisibility to encourage 'pro-social' behaviour towards them versus avoiding homophobia, respectively.

Evident in the narratives from the present study about belonging to a gay or lesbian organisation, is an attempt, as noted by Alan, 'to be like other people ... what make us unique and trying to equalise myself with another person means that I regard how other people behave as normal' (Alan, gay, Arts). This recalls Asencio's (2011:337) argument that homogenous homosexual spaces may reinforce homonormativity as it may reinforce 'the norms and practices within the gay community that support heteronormativity and marginalise certain forms of gender and sexuality'. This was echoed by a gay participant, Santo, who believes:

'[T] hat visible gay groups sometimes lose their focus on being different and they start to pursue equality with heterosexuals, since heterosexuality is regarded as normal; these groups then try to reinforce normality according to what is considered normal by a heterosexual community.' (Santo, gay, Engineering)

10.Emphasis added 
According to Francis (2017b), in his critical engagement with Kumashiro (2002) and Francis and Msibi's (2011) work, it may further reinforce heterosexism and further 'marginalise' sexual minorities as 'deviant', possibly resulting in further internalised homophobia, silence and isolation by sexual minorities (cf. Francis 2017b:25).

The narratives of two participants (Dee and Thinus) suggest that while safe spaces may be 'safer' for some sexual minorities, it may not be easy for those who have not disclosed their sexuality to engage with others in such spaces, particularly when they are classrooms, offices and buildings. These marginalised spaces, according to Fox (2007), tend to further exacerbate the potential for homophobic discrimination and may further reinforce compulsory heterosexuality. According to Van den Berg (2016), this separatist stance adopted by safe spaces might be problematic, as it upholds the idea of a single and homogeneous identity category for homosexual students and its separation from a potentially oppressive and dominant heteronormative culture; also tending to, contradictorily, make them both 'invisible' and 'too visible' (cf. De Wet et al. 2016).

The preceding views (whether in favour of or against compulsory heterosexual roles), in fact, contradictorily challenge and uphold the centrality of heteronormativity (Jackson \& Scott 2010), insofar as these participants, on the one hand, display liberationist and queer theoretical tendencies to challenge gender and sexual identity stereotypes and, on the other hand, tend to display assimilationist inclinations insofar as they seek to emphasise 'sameness' and association with heterosexuality (Van den Berg 2016). Such laudable attempts notwithstanding, a liberationist tendency may, contradictorily, both transgress and reinforce heteronormativity, insofar as those who refute heterosexual ideals through emphasising their differences as opposed to similarities with heterosexuality, may risk further 'othering' and 'objectification' (cf. De Wet et al. 2016; Rothmann 2016; Rothmann \& Simmonds 2015) of the supposedly uniquely different gay and lesbian identity within a heteronormative campus context, rather than only critiquing it.

Another limitation of safe spaces is the exacerbation of naiveté by students owing to the 'false' sense of security they may create (cf. Fox \& Ore 2010). One lesbian arts student, Batso, mentioned that she has never faced assault while on campus; she also attributed her positive experiences to the progress the campus is making in providing an opportunity for forming gay and lesbian societies, a thought evident in the work of Garcia-Alonso (2004). From a queer theoretical stance, one should be wary to assume that such separate (or exclusive) spaces and a student's individual agency indicate complete acceptance by the country's larger cultural scenario (cf. Jackson \& Scott 2010). It may rather address the continuing efforts of sexual minorities to assimilate into either exclusively homonormative spaces or conform to the mainstream and 'tolerant' heteronormative gendered and sexual context to avoid potential discrimination (cf. Atkinson \& De Palma 2009; Milani \& Wolff 2015). Joining gender and sexually diverse student organisations, students simultaneously (if unwittingly) enact heteronormative and homonormative sexual identities, as they may 'naturalise, normalise and legitimise some expressions of same-sex desire, at the expense of others', thus assimilating into a 'separate, private and nonpolitical sexual culture' without questioning the dominance of heteronormativity (Milani \& Wolff 2015:67).

\section{Conclusion and recommendations}

Participants emphasised the capacity of safe spaces to defend the rights of gay and lesbian students through, among others, empowerment. Safe spaces were also seen as bringing about sensitisation on issues related to sexual diversity and providing safe social networking and supportive spaces, possibly contributing to improving the healthy development and functioning of gay and lesbian students and improved self-esteem and confidence. Pertaining to the limitations, some of the students did not regard safe spaces as important or necessary as they may tend to create an exclusive and marginalised community and simultaneously exacerbate the potential for homophobic discrimination against sexual minorities.

From the findings, it appeared that all participants were unaware of the policies that protect the rights of gay and lesbian students; furthermore, the experiences they addressed underlined the need to direct attention to the implementation and potential restructuring of institutional policies to inform students of their rights on campus. A multidimensional strategy of inclusion and support is required to move the institution beyond access and beyond safety. Institutions should encourage an appreciation of diversity in these contexts and avoid the reinforcement of homonormative and gay sensibility stereotypes that may lead to further exclusion from within the gay and lesbian community (cf. Brown 2018; Poynter \& Washington 2005; Rothmann 2014). In keeping with the arguments of Lesch et al. (2017) at their research site, the NWU management is commended for creating an inclusionary climate for gender and sexually diverse students. Management is, however, encouraged to further intervene and restructure the existing human rights policy and diversity statement, so that explicit references are made to the protection of gender and sexually diverse persons. Likewise, the university should annually conduct awareness campaigns on diversity issues. Management should be encouraged to initiate and support workshops, seminars, conferences and courses on the lived experiences of the gay and lesbian community, in general, and their students/staff constituents in particular. It would also be significant if student counselling centre and university health centre staff are trained on gender and sexual diversity issues.

The diverse experiences of gay and lesbian students on the campus, informed by their personal fears; the impact of societal and campus culture, that separate venues or societies 
may exacerbate their visibility, which may be problematic for some; that allies (e.g. openly gay and lesbian lecturers) too may face adversity if they assisted students; problems associated with the 'normalisation' of heteronormativity - all contribute to deciding whether or not such spaces are necessary. With visibility being most important to gay and lesbian students, findings suggest that the introduction of formal policies may be essential for decisions on the disclosure of their identities. Furthermore, there should be an engagement with management to encourage an awareness of the importance associated with creating awareness among students and staff about the particular policies that centre on the protection of the gay and lesbian community. Restructuring these policies may also contribute to the declaration of their identities, serve as indicator of the safety measures provided for gay and lesbian students, and how these safety measures, through formal policies, may enable these students to report incidents associated with hate crimes on campus.

\section{Acknowledgements}

This article is based on the master's dissertation of Tshanduko Tshilongo at the North-West University (2018), entitled: 'Exploring the need for safe spaces for lesbian and gay students of the North-West University Potchefstroom Campus' by Tshanduko Tshilongo, available here: https:/ / dspace.nwu.ac.za/bitstream / handle/10394/28292/ Tshilongo_T_2018.pdf?sequence $=1 \&$ isAllowed $=\mathrm{y}$.

\section{Competing interests}

The authors have declared that no competing interests exist.

\section{Authors' contributions}

J.R. was the research supervisor for the master's study. T.T. was responsible for the fieldwork, data analysis and writing-up of the master's dissertation. J.R. and T.T. collaborated on the conceptualisation, writing-up and editing of the article.

\section{Ethical consideration}

Ethical clearance to conduct the study was obtained from the Research Ethics Committee of the Faculty of Arts, NorthWest University, Potchefstroom Campus (Ethical Clearance Number: 00471-15-A7, 2015-11-12).

\section{Funding}

This research received no specific grant from any funding agency in the public, commercial or not-for-profit sectors.

\section{Data availability statement}

Data sharing is not applicable to this article as no new data were created or analysed in this study.

\section{Disclaimer}

The views and opinions expressed in this article are those of the authors and do not necessarily reflect the official policy or position of any affiliated agency of the authors.

\section{References}

Ackerly, B. \& True, J., 2010, Doing Feminist research in political \& social science, Palgrave MacMillan, London.

Alvarez, S.D. \& Schneider, J., 2008, 'One college campus's need for a safe zone: A case study', Journal of Gender Studies 17(10), 71-74. https://doi.org/10.1080/ 09589230701838461

Arndt, M. \& De Bruin, G., 2006, 'Attitudes toward lesbians and gay men: Relations with gender, race and religion among university students', Psychology in Society 33, $16-30$.

Asencio, M., 2011, “'Locas", respect, and masculinity: Gender conformity in migrant Puerto Rican gay masculinities', Gender \& Society 25(3), 335-354. https://doi. org $/ 10.1177 / 0891243211409214$

Atkinson, E. \& De Palma, R., 2009, 'Un-believing the matrix: Queering consensual heteronormativity', Gender and Education 21(1), 17-29. https://doi.org/10.1080/ 09540250802213149

Babbie, E. \& Mouton, J., 2001, The practice of social research, Oxford University Press, New York.

Barrett, M., L. DiGiovine, Holmberg, M. \& Gudelunas, D., 2007, The collegiate closet: A policy report, pp. 1-23, Fairfield University, Fairfield.

Beemyn, G. \& Rankin, S.R., 2016, 'Creating a gender-inclusive campus', in Y.M. Miguel \& S. Tobias (eds.), Trans studies: The challenge to hetero/homo normativities, pp. 21-32, Rutgers University Press, New York.

Bhana, D., 2012, 'Understanding and addressing homophobia in schools: A view from teachers', South African Journal of Education 32(3), 307-318. https://doi. org/10.15700/saje.v32n3a659

Bhana, D., 2014, “"Managing” the rights of gays and lesbians: Reflections from some South African secondary schools', Education, Citizenship and Social Justice 9(1), 67-80. https://doi.org/10.1177/1746197913497663

Biaggio, M., Orchard, S., Larson, J., Petrino, K. \& Mihara, R., 2003, 'Guidelines for gay/ lesbian/bisexual affirmative educational practices in graduate psychology programs', Professional Psychology, Research and Practice 34(5), 548-554. https://doi.org/10.1037/0735-7028.34.5.548

Biegel, S., 2010, The right to be out: Sexual orientation and gender identity in America's public schools, University of Minnesota Press, Minneapolis, MN.

Birkett, M., Koenig, B. \& Espelage, D., 2009, 'LGB and questioning students in schools: The moderating effects of homophobic bullying and school climate on negative outcomes', Journal of Youth Adolescence 38(7), 989-1000. https://doi.org/10. 1007/s10964-008-9389-1

Boostrom, R., 1998, “'Safe spaces”: Reflections on an educational metaphor', Journal of Curriculum Studies 30(4), 397-408. https://doi.org/10.1080/002202798183549

Braun, V. \& Clarke, V., 2006, 'Using thematic analysis in psychology', Qualitative ResearchinPsychology3(2),77-101.https://doi.org/10.1191/1478088706qp063oa

Brown, A., 2018, 'Geographies of heteronormativity: The source of symbolic homophobic violence at a South African university', African Safety Promotion: A Journal of Injury and Violence Promotion 16(2), 9-20.

Brown, A. \& De Wet, A., 2018, 'Responding to sexual diversity in education', in A. De Wet (ed.), Diversity and difference in South African schools: An education Law perspective, pp. 119-146, Juta \& Co, Cape Town.

Bryman, A., 2016, Social research methods, International edn., Oxford University Press, Oxford.

Butler, A.H., Alpaslan, A.H., Strümpher, J. \& Astbury, G., 2003, 'Gay and lesbian youth experiences of homophobia in South African secondary education', Journal of gay and lesbian issues in education 1(2), 3-28. https://doi.org/10.1300/ J367v01n02_02

Cass, V.C., 1979, 'Homosexual identity formation: A theoretical model', Journal of Homosexuality 4(3), 219-235. https://doi.org/10.1300/J082v04n03_01

Chang, Y., 2005, 'Through queers' eyes: Critical educational ethnography in queer studies', The Review of Education, Pedagogy, and Cultural Studies 27(2), 171-208. https://doi.org/10.1080/10714410590963857

Consortium of Higher Education LGBT Resource Professionals, 2016, Vision and mission statement, Home Page, viewed 22 November 2016, from http://www. Igbtcampus.org.

Corrigan, P. \& Matthews, A., 2003, 'Stigma and disclosure: Implications for coming out of the closet', Journal of Mental Health 12(3), 235-248. https://doi. org/10.1080/0963823031000118221

Creswell, J.W. \& Creswell, J.D., 2018, Research design: Qualitative, quantitative \& mixed methods approaches, 5th edn., Sage, London.

De Palma, R. \& Francis, D., 2014, 'South African life orientation teachers: (Not) teaching about sexual diversity', Journal of Homosexuality 61(12), 1687-1711. https://doi.org/10.1080/00918369.2014.951256

Department of Basic Education, 2019, Comprehensive sexuality education: Scripted lessons, viewed 17 November 2019, from https://www.education.gov.za/Home/ ComprehensiveSexualityEducation.aspx 
Department of Education, 1997, White paper 3: A programme for the transformation of higher education, DoE, Pretoria.

De Wet, A., 2017, 'Human rights and sexuality - Reimagining the language of equality towards transformation in and through education', South African Journal of Higher Education 31(6), 113-132. https://doi.org/10.20853/31-6-1628

De Wet, A., Rothmann, J. \& Simmonds, S., 2016, 'Human rights: Protecting sexual minorities or reinforcing the boundaries of "the closet"?', South African Review of Sociology 47(3), 85-109. https://doi.org/10.1080/21528586.2016.1163291

Donaldson, N., 2015, 'What about the queers? The institutional culture of heteronormativity and its implications for queer staff and students', in P. Tabensky \& S. Matthews (eds.), Being at home. Race, institutional culture and transformation at South African higher education institutions, pp. 130-146, University of KwaZulu-Natal Press, Pietermaritzburg.

Eide, E., 2010, 'Strategic essentialism and ethnification. Hand in glove?', Nordicom Review 31(2), 63-78. https://doi.org/10.1515/nor-2017-0130

Epprecht, M., 2010, 'Understanding homophobia in Africa today', Perspectives 4(10), 10-15. https://doi.org/10.2979/africatoday.58.1.55

Etheridge, J., 2019, Fake news hurting debate on Comprehensive Sexuality Education - Department, viewed 17 November 2019, from https://www.news24.com/ SouthAfrica/News/fake-news-hurting-debate-on-comprehensive-sexualityeducation-department-20191117

Evans, N.J., 2000, 'Creating a positive learning environment for gay, lesbian, and bisexual students', New Directions for Teaching and Learning 2000(82), 81-87. https://doi.org/10.1002/tl.8208

Evans, N.J., 2002, 'The impact of an LGBT safe zone project on campus climate', Journal of College Student Development 43(4), 522-539.

Fetner, T. \& Elafros, A., 2015, 'The GSA difference: LGBTQ and ally experiences in high schools with and without gay-straight alliances', Social Sciences 4(3), 563-581. https://doi.org/10.3390/socsci4030563

Finkel, M.J., Storaasli, R.D., Bandele, A. \& Schaefer, V., 2003, 'Diversity training in graduate school: An exploratory evaluation of the Safe Zone project', Professional Prychology: Research and Practice 34(5), 555-561. https://doi.org/10.1037/0735Psychology: Rese

Foucault, M., 1980, The history of sexuality, vol. 1, Pantheon, New York.

Fox, C., 2007, 'From transaction to transformation: (En)countering white heteronormativity in "safe spaces"', College English 69(5), 496-511.

Fox, C. \& Ore, R.E., 2010, '(Un)covering normalized gender and race subjectivities in LGBT safe spaces', Feminist Studies 36(3), 629-649.

Francis, D., 2013, “'You know the homophobic stuff is not in me, like us, it's out there". Using Participatory Theatre to challenge heterosexism and heteronormativity in a South African school', South African Journal of Education 33(4), 1-14. https://doi. South African school', South Afric
org/10.15700/201412171338

Francis, D., 2017a, 'Homophobia and sexuality diversity in South African schools: A review', Journal of LGBT Youth 14(4), 359-379. https://doi.org/10.1080/1936165 3.2017.1326868

Francis, D., 2017b, Troubling the teaching and learning of gender and sexual diversity in South African education, Palgrave MacMillan, New York.

Francis, D., 2019, “"Keeping it straight" what do South African queer youth say they need from sexuality education?', Journal of Youth Studies 22(6), 772-790. https:// doi.org/10.1080/13676261.2018.1539223

Francis, D. \& Msibi, T., 2011, 'Teaching about heterosexism: Challenging homophobia in South Africa', Journal of LGBT Youth 8(2), 157-173. https://doi.org/10.1080/19 361653.2011.553713

Garcia-Alonso, P.M., 2004, 'From surviving to thriving: An investigation of the utility of support groups designed to address the special needs of sexual minority youth in public high schools', Doctoral dissertation, Dissertation Abstracts International, public high schools', Doctoral dissertation, Disse
$65(3 A)$, (UMI No. 3126026), Loyola University.

Ghaziani, A., 2015, 'Gay enclaves face prospect of being passe': How assimilation affects the spatial expressions of sexuality in the United States', Internationa Journal of Urban and Regional Research 39(4), 756-771. https://doi. org/10.1111/1468-2427.12209

Grace, A.P., 2006, 'Writing the queer self: Using autobiography to mediate inclusive teacher education in Canada', Teaching and Teacher Education 22(7), 826-835. https://doi.org/10.1016/j.tate.2006.04.026

Grace, A.P., 2015, Growing into resilience: Sexual and gender minority youth in Canada, University of Toronto Press, Toronto, ON.

Grace, A.P., 2017, 'Two good gay teachers: Pioneering advocate-practitioners confronting homophobia in schooling in British Columbia, Canada', Irish Educationa Studies 36(1), 43-56. https://doi.org/10.1080/03323315.2017.1289701

Grace, A.P. \& Benson, F.J., 2000, 'Using autobiographical queer life narratives of teachers to connect personal, political and pedagogical spaces', International Journal of Inclusive Education 4(2), 89-109. https://doi.org/10.1080/136031100284830

Graziano, K.J., 2004, 'Coming out on a South African university campus: Adaptations of gay men and lesbians', Society in Transition 35(2), 273-286. https://doi.org/10 .1080/21528586.2004.10419119

Griffin, P., D’Errico, K., Harro, B. \& Schiff, T., 2007, 'Heterosexism curriculum design', in M. Adams, L.A. Bell \& P. Griffin (eds.), Teaching for diversity and social justice, pp. 195-218, Routledge, New York.

Hames, M., 2007, 'Sexual identity and transformation at a South African university', Social Dynamics 33(1), 52-77. https://doi.org/10.1080/02533950708628743

Harper, G.W., Omar Bashir Jamil, M.P.H. \& Wilson, B.D.M., 2007, 'Collaborative community-based research as activism: Giving voice and hope to lesbian, gay, and bisexual youth', Journal of Gay \& Lesbian Psychotherapy 11(3-4), 99-119. https:// doi.org/10.1300/J236v11n03_06
Hind, T., 2004, Being real: Promoting the emotional health and mental well-being of lesbian, gay and bisexual young people accessing PACE youth work services, Project for Advice Counselling and Education, London.

Jackson, S. \& Scott, S., 2010, Theorizing sexuality, McGraw Hill, New York.

Jagessar, V. \& Msibi, T., 2015, “'It's not that bad": Homophobia in the residences of a university in KwaZulu-Natal, Durban, South Africa', Agenda 29(1), 63-73. https:// doi.org/10.1080/10130950.2015.1022984

Jagose, A., 1996, Queer theory: An introduction, New York University Press, New York. Judge, M., 2017, Blackwashing homophobia: Violence and the politics of sexuality, gender and race, Routledge, London.

Kumashiro, K., 2002, Troubling education: Queer activism and anti-oppressive pedagogy, Routledge Falmer, New York.

Lesch, E., Brits, S. \& Naidoo, N.T., 2017, "'Walking on eggshells not to offend people": Experiences of same-sex student couples at a South African university', South African Journal of Higher Education 31(4), 127-149. https://doi.org/10. 20853/31-4-893

Macgillivray, I., 2004, Sexual orientation and school policy, Rowman \& Littlefield, Lanham, ND.

McArthur, T., 2015, 'Homophobic violence in a Northern Cape school: Learners confront the issue', Agenda 29(3), 1-7. https://doi.org/10.1080/10130950.2015.1 056587

Mendos, L.R., 2019, State sponsored homophobia, 13th edn., ILGA, Geneva.

Milani, T.M. \& Wolff, B., 2015, 'Queer skin, straight masks: Same-sex weddings and the discursive construction of identities and effects on a South African website', Critical Arts 29(2), 165-182. https://doi.org/10.1080/02560046.2015.1039203

Msibi, T., 2009, 'Not crossing the line: Masculinities and homophobic violence in South Africa', Agenda 23(80), 50-54. https://doi.org/10.1080/10130950.2009. 9676240

Msibi, T., 2013, 'Denied love: Same-sex desire, agency and social oppression among African men who engage in same-sex relations', Agenda 27(2), 105-116. https:// doi.org/10.1080/10130950.2013.811014

Msibi, T., 2015, 'The teaching of sexual and gender diversity issues to pre-service teachers at the University of KwaZulu-Natal: Lessons from student exam responses', Alternation 21(12), 385-410.

Munyuki, C. \& Vincent, L.D., 2017, “"It's tough being gay”: Gay, lesbian and bisexual students' experiences of being "at home" in South African university life', South African Journal of Higher Education 31(4), 14-33. https://doi. org/10.20853/31-2-869

Mwaba, K., 2009, 'Attitudes and beliefs about homosexuality and same-sex marriage among a sample of South African students', Social Behaviour and Personality 37(6), 801-804. https://doi.org/10.2224/sbp.2009.37.6.801

Nduna, M., Mthombeni, A., Mavhandu-Mudzusi, A.H. \& Mogotsi, I., 2017, 'Studying sexuality: LGBTI experiences in institutions of higher education in Southern Africa', South African Journal of Higher Education 31(4), 1-13. https://doi.org/10. 20853/31-4-1330

Nel, J. \& Slatter, L., 2019, 'Skok in skole: Minder seks, asseblief!', Rapport 1.

Nel, J.A., Rich, E. \& Joubert, K., 2007, 'Lifting the veil: Experiences of gay men in a therapy group', South African Journal of Psychology 37(2), 284-306. https://doi. org/10.1177/008124630703700205

Neumann, S.L., 2005, "Creating a "safe zone" for sexual minority students in the psychology classroom', Teaching of Psychology 32(2), 121-123.

North-West University (NWU), 2006, Diversity statement, North-West University Institutional Office, Potchefstroom.

North-West University (NWU), 2016, Human Rights Policy, North-West University Institutional Office, Potchefstroom.

O'Leary, Z., 2014, The essential guide to doing your research project, Sage, Los Angeles, CA.

Oswin, N., 2007, 'Producing homonormativity in neoliberal South Africa: Recognition, redistribution, and the equality project', Signs: Journal of Women in Culture and Society 32(3), 649-669. https://doi.org/10.1086/510337

Payne, E.C. \& Smith, M., 2011, 'The reduction of stigma in schools: A new professional development model for empowering educators to support LGBTQ
students', Journal of LGBT Youth 8(2), 174-200. https://doi.org/10.1080/19361 students', Journal
653.2011 .563183

Petrovic, J. \& Rosiek, J., 2003, 'Heteronormative subjectivities of Christian preservice teachers', Equity and Excellence in Education 36(2), 161-169. https://doi. teachers', Equity and Excellence
org/10.1080/10665680303509

Plummer, K., 2015, Cosmopolitan sexualities: Hope and humanist imagination, Polity Press, Cambridge.

Poynter, K.J. \& Tubbs, N.J., 2008, 'Safe zones: Creating LGBT safe space ally programs', Journal of LGBT Youth 5(1), 121-132. https://doi.org/10.1300/J524v05n01_10

Poynter, K.J. \& Washington, D., 2005, 'Multiple identities: Creating community on campus for LGBT students', New Directions for Student Services 2005(111), 41-47. https://doi.org/10.1002/ss.172

Rankin, S.R., 2006, 'LGBTQA students on campus: Is higher education making the grade?' Journal of Gay and Lesbian Issues in Education 3(2-3), 111-117. https:// doi.org/10.1300/J367v03n02_11

Ratts, M.J., Kaloper, M., McReady, C., Tighe, L., Butler, S.K., Dempsey, K. et al., 2013 'Safe space programs in K-12 schools: Creating a visible presence of LGBTQ allies', Journal of LGBT Issues in Counselling 7(4), 387-404. https://doi.org/10.1080/155 38605.2013.839344 
Reddy, V., 2010, 'Identity, Law, Justice. Thinking about sexual rights and citizenship in post-apartheid South Africa', Perspectives 4(10), 18-23.

Republic of South Africa (RSA), 1996, Constitution of the Republic of South Africa (Act no. 108 of 1996), viewed 01 November 2019, from http://www.justice.gov.za/ legislation/constitution/SAConstitution-web-eng.pdf

Rich, A., 2003, 'Compulsory heterosexuality and lesbian existence', Women: Sex and Sexuality 5(4), 631-660. https://doi.org/10.1353/jowh.2003.0079

Richardson, E., 2008, 'Researching LGB youth in post-apartheid South Africa', Journal of Gay and Lesbian Issues in Education 3(2/3), 135-140. https://doi.org/10.1300/ J367v03n02_15

Robinson, B., 2012, 'Is this what equality looks like?', Sexuality Research and Socia Policy 9(4), 327-336. https://doi.org/10.1007/s13178-012-0084-3

Robinson, K.H. \& Ferfolja, T., 2001, “"What are we doing this for?" Dealing with lesbian and gay issues in teacher education', British Journal of Sociology of Education 22(1), 121-133. https://doi.org/10.1080/01425690020030828

Robson, R., 2002, 'Assimilation, Marriage, and Lesbian Liberation', Temple Law Review 75(4), 710-820.

Rothmann, J., 2014, '(De)constructing the heterosexual/homosexual binary: The identity construction of gay male academics and students in South African tertiary education', Unpublished Doctoral thesis, Department of Sociology, North-West University, Potchefstroom.

Rothmann, J., 2016, 'The (de)professionalisation of the gay male academic identity: Locking the closet door on South African university campuses', South African Review of Sociology 47(4), 40-59. https://doi.org/10.1080/21528586.2016.1182444

Rothmann, J., 2017, 'The role of self-reflexivity on the part of gay male academics on South African university campuses', Acta Academica 49(1), 1-31. https://doi. org/10.18820/24150479/aa49i1.4

Rothmann, J., 2018, 'A social constructionist approach to resilience for lesbian, gay, bisexual, transgender, intersex, queer and/or questioning academics and students in South African universities', Transformation in Higher Education 3(0), 1-8. a34. https://doi.org/10.4102/the.v3i0.34
Rothmann, J. \& Simmonds, S., 2015, “Othering" non-normative sexualities through objectification of "the homosexual": Discursive discrimination by pre-service teachers', Agenda 103(1), 116-126. https://doi.org/10.1080/10130950.2015.10 10288

Rumens, N., 2011, Queer company: The role and meaning of friendship in gay men's work lives, Ashgate, Burlington.

Sanlo, R., Rankin, S. \& Schoenberg, R. (eds.), 2002, Our place on campus: Lesbian, gay bisexual, transgender services and programs in higher education, Greenwood Press, Westport, CT.

Seidman, S., 2003, The social construction of sexuality, W.W. Norton and Company, New York.

Sithole, S., 2015, 'Challenges faced by gay, lesbian, bisexual and transgender (GLBT) students at a South African University', The Journal for Transdisciplinary Research in Southern Africa 11(4), 193-219. https://doi.org/10.4102/td.v11i4.54

Spivak, G.C., 1987, In other worlds: Essays in cultural politics, Methuen, New York.

Tshilongo, T., 2018, 'Exploring the need for safe spaces for lesbian and gay students of the North-West University Potchefstroom Campus', Master's dissertation, NorthWest University, Potchefstroom.

Van den Berg, E., 2016, “"The closet": A dangerous heteronormative space', The South African Review of Sociology 47(3), 25-44. https://doi.org/10.1080/21528586.201 6.1182445

Walsh-Haines, G., 2012, 'The Egyptian Blogosphere: Policing gender and sexuality and the consequences for queer emancipation', Journal of Middle East Women's Studies 8(3), 41-62. https://doi.org/10.2979/jmiddeastwomstud.8.3.41

Warner, M., 1991, 'Fear of a queer planet', Social Text 9(14), 3-17.

Warren, C., 2008, 'Fieldwork in the gay world: Issues in phenomenological research', Gender and Research 33(4), 133-145. https://doi.org/10.1111/j.1540-4560.1977. tb02524.x

Wilson, S. \& MacLean, R., 2011, Research methods and data analysis for psychology, McGraw-Hill, London. 